\title{
Persistence on biologic DMARD monotherapy after achieving rheumatoid arthritis disease control on combination therapy: retrospective analysis of corrona registry data
}

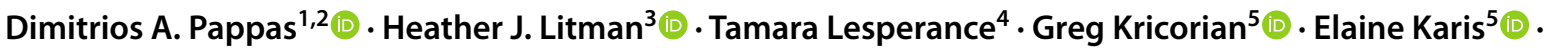 \\ Sabrina Rebello ${ }^{1}$ (D) . Winnie Hua ${ }^{3}$ (D) . Neil A. Accortt ${ }^{6}$ (D) Scott Stryker $^{6}$ (D)
}

Received: 3 February 2020 / Accepted: 28 July 2020 / Published online: 2 September 2020

(c) The Author(s) 2020

\begin{abstract}
Biological disease-modifying antirheumatic drugs (bDMARDs) monotherapy may enhance adherence and decrease adverse events compared to combination therapy with conventional synthetic DMARDs (csDMARDs); however, persistence with bDMARD monotherapy has not been extensively studied. We explore persistence of etanercept monotherapy and monotherapy with other tumor necrosis factor inhibitors (TNFis) among patients first achieving remission/low disease activity (LDA) while on combination therapy with csDMARDs and a TNFi. Using Corrona registry data, the percentage of patients persistent with the index TNFi (etanercept versus other TNFis) over 6 and 12 months was determined. Factors influencing persistence and treatment patterns at 6 and 12 months were examined. Among 617 eligible patients, $56 \%$ of 182 patients on etanercept and $45 \%$ of 435 patients on other TNFis persisted with monotherapy at 6 months, $46 \%$ and $33 \%$, respectively, at 12 months. Across first-line and subsequent biologic DMARDs, etanercept persistence was greater than other TNFi persistence by $10.8 \%(95 \%$ CI $2.1 \%, 19.6 \%)$ at 6 months and $11.4 \%(95 \%$ CI $0.9 \%, 21.9 \%)$ at 12 months. Patients on other TNFis were more likely to require reintroduction of csDMARD after 6 months (45\% versus 35\% for etanercept). Remission was the key predictor of persistence for both etanercept and other TNFi monotherapies. This retrospective, cohort study of registry data reflecting real-world practice indicates patients who achieve remission/LDA with combination csDMARD and TNFi therapy may successfully transition to TNFi monotherapy. Patients on etanercept monotherapy experienced greater persistence and less frequent reintroduction of a csDMARD than was observed for patients on other TNFi monotherapies.
\end{abstract}

Keywords TNF inhibitors · Etanercept $\cdot$ Methotrexate $\cdot$ Antirheumatic drugs $\cdot$ Disease-modifying antirheumatic drugs ·

Arthritis · Rheumatoid

Dimitrios A. Pappas

dpappas@corrona.org

Heather J. Litman

hlitman@corrona.org

Tamara Lesperance tamara.tt2@gmail.com

Greg Kricorian

gkricori@amgen.com

Elaine Karis

ekaris@amgen.com

Sabrina Rebello

sdeveikis@yahoo.com

Winnie Hua

whua@corrona.org

Neil A. Accortt

naccortt@amgen.com
Scott Stryker

sstryker@amgen.com

1 Department of Epidemiology and Outcomes Research, Corrona, LLC, Waltham, MA, USA

2 Columbia University College of Physicians and Surgeons, Columbia University, $630 \mathrm{~W}$ 168th St, P\&S Building, Suite 10-445, New York, NY 10032, USA

3 Department of Biostatistics, Corrona, LLC, Waltham, MA, USA

4 DOCS Global, Inc., North Wales, PA, USA

5 US Medical Affairs, Amgen Inc., Thousand Oaks, CA, USA

6 Center for Observational Research, Amgen Inc., Thousand Oaks, CA, USA 


\section{Introduction}

Rheumatoid arthritis (RA) is a chronic, systemic autoimmune disease affecting the synovial lining of the joints [1], with an estimated prevalence of $0.5-1.0 \%$ [2]. In the United States, RA has an estimated annual incidence of 41 cases per 100,000 persons, is estimated to affect approximately 1.5 million adults [3], and is associated with extensive morbidity and reduced quality of life [4]. When the disease is insufficiently treated, joint damage and extraarticular manifestations can result, accompanied by irreversible disability $[1,2]$.

There is currently no known cure for RA [1]; nonetheless, the current European League Against Rheumatism (EULAR), American College of Rheumatology (ACR), and Asia Pacific League of Associations for Rheumatology (APLAR) treatment guidelines all recognize the achievement of remission or low disease activity (LDA) as a realistic goal for treat-to-target strategies [5-7]. Guidelines recommend conventional synthetic disease-modifying agents (csDMARDs) as first-line treatment for RA [5-7]. For patients not achieving sufficient disease control with csDMARDs alone, the addition of biologic DMARDs (bDMARDs) is recommended [5-7]. Although the guidelines are clear about the role of combination therapy, there is less clarity about the treatment approach once remission or LDA has been achieved [5-7]. For patients in sustained remission, no specific guidance is provided for tapering or discontinuing treatment in patients on combination therapy. Given that the use of multiple therapies may compromise patient adherence [8], and that $10-37 \%$ of patients with RA cannot tolerate methotrexate $[9,10]$, the option of monotherapy with bDMARDs is of interest, particularly as adherence to bDMARDs appears to be higher than adherence to csDMARDs, such as methotrexate [11]. Monotherapy with bDMARDs may enhance adherence and decrease the chances of adverse events compared to combination therapy with csDMARDs, such as methotrexate [12]. However, the persistency of TNFi monotherapy after achieving disease control on combination therapy has not been extensively investigated.

TNFis are the most commonly used bDMARDs for the treatment of RA. TNFis include monoclonal antibodies against TNF and etanercept [5-7]. Etanercept is a dimeric fusion protein consisting of the binding portion of the TNF receptor linked to human immunoglobulin [13] and does not lyse cells expressing TNF- $\alpha$ [14]. Unlike monoclonal antibodies to TNF $[15,16]$, etanercept has not been associated with the formation of neutralizing antidrug antibodies [17]. Methotrexate has been found to reduce the development of antidrug antibodies to TNFis [18]. Since etanercept does not induce neutralizing antibodies like monoclonal TNFis, the use of methotrexate with etanercept is not necessary to prevent the formation of neutralizing antidrug antibodies, and for this reason, the continued use of methotrexate in patients treated with etanercept may not be needed in patients who have achieved good disease control.

The primary objective of this retrospective, cohort study and analysis of existing data from the Corrona registry reflecting real-world clinical practice was to explore persistence of etanercept and other TNFi monotherapy after achieving remission/LDA while on combination therapy with csDMARDs. The study was based on data from the Corrona registry, representing real-world clinical practice in the United States for patients with RA.

\section{Materials and methods}

\section{Study setting}

Data for this analysis were obtained from the Corrona registry, an independent, prospective, observational cohort of patients with physician-confirmed diagnosis of RA, regardless of fulfillment of any classification criteria [19], currently recruiting patients from 177 private practices and academic sites with 752 participating rheumatologists across 42 US states. As of August 31, 2017 (the study cutoff), data for 46,542 adult patients with RA had been collected.

All participating investigators obtained full institutional review board (IRB) approval for human subject research. Sponsor approval and continuing review were obtained through a central IRB (New England Independent Review Board, NEIRB No. 120160610). For academic investigative sites without a waiver to use the central IRB, full board approval was obtained from the respective governing IRBs; documentation of approval was submitted to the Sponsor before initiating any study procedures. All registry participants provided written informed consent before participating.

\section{Study design and patient identification}

This is a retrospective analysis of data from patients with RA enrolled in the Corrona registry. The study period was October 1, 2001, through August 31, 2017. Data from adults $\geq 18$ years old with a physician-confirmed diagnosis of RA who had achieved remission or LDA on combination therapy with TNFi and csDMARD and then discontinued the csDMARD were analyzed. The index date was the date the patient discontinued csDMARD therapy and continued on TNFi monotherapy. To be included in the analysis, patients had to have a 6-month follow-up visit after the index date. 
Remission was defined as Clinical Disease Activity Index (CDAI) score $\leq 2.8$; LDA was defined as CDAI score $>2.8$ and $\leq 10.0[6,20]$. TNFis included adalimumab, certolizumab pegol, etanercept, golimumab, and infliximab; csDMARDs included methotrexate, hydroxychloroquine, leflunomide, and sulfasalazine.

Based on the treatment prescribed in the period immediately prior and up to the index date, patients were divided into two separate groups: those who were initially treated with etanercept and a csDMARD and those who were initially treated with other TNFis and csDMARD.

\section{Study outcomes}

The primary outcome was the percentage of patients who remained persistent on monotherapy with the index TNFi. Persistence was defined as continuous use of the index monotherapy medication without any treatment gap $\geq 30$ days during the 6- or 12-month period after the index date. Previous bDMARD experience has been shown to affect persistence [21-23]; therefore, persistence was explored separately for bDMARD-naïve and bDMARD-experienced patients. Demographic and clinical characteristics as predictors of persistence were assessed.

Secondarily, we evaluated the treatment patterns during the same 6- to 12-month period, including patients who discontinued their index TNFi, switched to another bDMARD, discontinued the TNFi and switched to csDMARD monotherapy, added csDMARD therapy, or escalated the TNFi dose. Finally, we considered the effect of prior exposure to bDMARD therapy and other factors on the odds of a patient continuing to persist on monotherapy by their 6-month visit.

\section{Statistical considerations}

Baseline demographics and disease characteristics at the index date (i.e., the time of discontinuation of the csDMARD) were summarized separately for etanercept and other TNFis and were stratified by prior bDMARD exposure (naïve versus experienced).

Persistence was explored for the entire etanercept cohort and for the other TNFi cohort, and also separately stratified by prior bDMARD exposure. Chi-square tests were used to compare proportions, and $t$ tests were used to compare continuous measures between patients on etanercept and those on other TNFi therapies. We also calculated a common value for the difference in persistence at the 6-month visit between etanercept and other TNFis across the bDMARD-naïve and bDMARD-experienced patients (stratified Mantel-Haenszel common risk difference). It was hypothesized that persistence according to prior bDMARD exposure for patients on monotherapy (etanercept versus other TNFi) was similar (Mantel-Haenszel tests calculated).
To identify the factors predictive of persistence, logistic regression models were fit; separate logistic regression models were fit for the etanercept and other TNFi monotherapy groups. Bivariate logistic regression models were first considered for selected variables, including demographic characteristics (age, sex, and race), clinical characteristics (duration of RA, anti-cyclic citrullinated peptide antibody [aCCP] status, and rheumatoid factor status), comorbidities (cardiovascular disease [i.e., coronary artery disease, myocardial infarction, coronary heart failure requiring hospitalization, acute coronary syndrome, unstable angina, cardiac revascularization procedure, cardiac arrest, and ventricular arrhythmia or other cardiovascular event], serious infection, or diabetes), and disease status (CDAI and physician global assessment [PGA]). Covariates that were statistically significantly associated with persistence on monotherapy $(p<0.05)$ were considered in multivariable models.

\section{Results}

\section{Patients}

Of the 46,542 adult patients with RA ever enrolled in the Corrona database, 10,413 patients were on a TNFi at the time of the analysis. 8202 patients had received a TNFi as part of a combination regimen with a csDMARD. Of these patients, 863 were in remission/LDA at the time the csDMARD was discontinued (index date); the 617 patients with a 6-month follow-up visit were included in this analysis. Of these, 182 patients were on etanercept monotherapy and 435 patients were on monotherapy with other TNFi therapies (Fig. 1).

Among patients on etanercept monotherapy and other TNFi monotherapy, 146 of $182(80.2 \%)$ and 274 of 435 (63.0\%) patients, respectively, had not received prior treatment with another bDMARD at any time during their enrollment in the Corrona database before initiation of the index biologic. When stratifying these patients, baseline characteristics were similar (Tables 1 and 2) except bDMARD-naïve patients on etanercept monotherapy were younger (mean, 55.5 versus 58.6 years; $p=0.024$ ), had a longer time in remission/LDA before discontinuation of the csDMARD (mean, 19.0 versus 15.9 months; $p=0.202$ ), and had a lower prevalence of cardiovascular disease (as determined at the index date: $0.7 \%$ versus $4.4 \%$; $p=0.04$ ) than bDMARD-naive patients on other TNFi monotherapy, although the latter outcomes were based on few events. Biologic DMARD-experienced patients on etanercept $(n=36)$ and other TNFi therapy $(n=161)$ also had similar baseline characteristics (Tables 1,2), except fewer bDMARD-experienced patients on etanercept monotherapy had received $>1$ prior bDMARDs $(8.3 \%$ versus 
Fig. 1 Patient identification. bDMARD, biologic diseasemodifying antirheumatic drug; csDMARD, conventional synthetic disease-modifying antirheumatic drug; ETN, etanercept; $L D A$, low disease activity; $R A$, rheumatoid arthritis; $T N F i$, tumor necrosis factor inhibitor

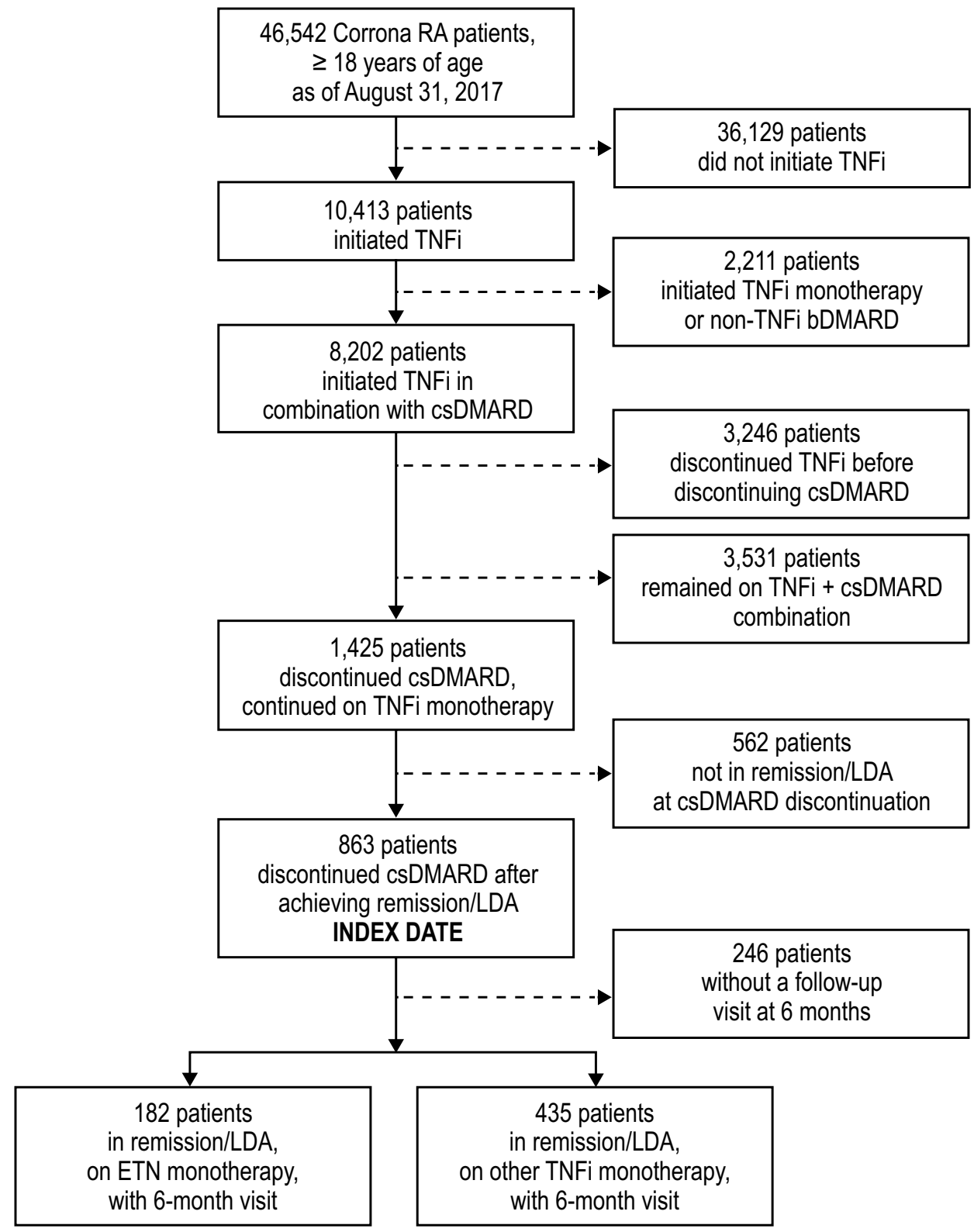

$27.3 \% ; p=0.016)$, patients on etanercept had been on bDMARD therapy longer than those on other TNFi therapy before the index visit (mean, 8.7 versus 5.7 months; $p=0.028$ ) and had a shorter time in remission/LDA before the discontinuation of the csDMARD (mean 10.6 versus 18.4 months; $p=0.091$ ), and a greater proportion of patients on etanercept monotherapy were currently using prednisone $(25.0 \%$ versus $9.9 \%$; $p=0.024)$.

Outcomes for two cohorts of patients were explored: those with a 6-month visit and those with a 12-month visit. Of the 617 patients included in the 6-month cohort, 120 patients on etanercept monotherapy and 307 patients on other TNFi therapy were also included in a 12-month cohort.

\section{Persistence}

Overall persistence among all patients at 6 months was 56\% for those on etanercept monotherapy and $45 \%$ for those on other TNFi monotherapy (crude risk difference 11.2\% [95\% CI 2.6\%, 19.8\%]; $p=0.02$ ). At 12 months, persistence among all patients on etanercept monotherapy (46\%) was higher than that for those on other TNFi monotherapy (33\%) at 12 months (crude risk difference, $12.6 \%$ [95\% CI $2.3 \%$, $23.0 \%] ; p=0.03)$.

For the 6-month cohort, when stratified by prior bDMARD exposure, a higher proportion of bDMARDnaive patients on etanercept were persistent with their index bDMARD (58\%) than those who were also 
Table 1 Baseline demographic and clinical characteristics among bDMARD-naïve and bDMARD-experienced patients at index date

\begin{tabular}{|c|c|c|c|c|}
\hline & \multicolumn{2}{|c|}{ bDMARD-naïve patients } & \multicolumn{2}{|c|}{ bDMARD-experienced patients } \\
\hline & $\operatorname{ETN}(n=146)$ & Other TNFi $(n=274)$ & $\operatorname{ETN}(n=36)$ & Other TNFi $(n=161)$ \\
\hline Age, mean (SD), years $[N]$ & $55.5(13.0)[146]^{*}$ & $58.6(13.7)[274]^{*}$ & $54.8(12.4)[36]$ & $57.6(13.1)[161]$ \\
\hline Female, $n(\%)[N]$ & $106(72.6)[146]$ & $194(71.1)[273]$ & $30(83.3)[36]$ & 117 (72.7) [161] \\
\hline White, $n(\%)[\mathrm{N}]$ & $127(87.0)[146]$ & $233(85.0)[274]$ & $29(80.6)[36]$ & $134(83.2)[161]$ \\
\hline Duration of RA, mean (SD), years $[N]$ & $8.8(8.5)[143]$ & $8.8(8.2)[273]$ & $11.5(9.1)[36]$ & $11.8(9.2)[157]$ \\
\hline RF positive, $n(\%)[N]$ & 69 (72.6) [95] & $152(76.4)[199]$ & 19 (82.6) [23] & $62(66.7)[93]$ \\
\hline aCCP antibody positive, $n(\%)[N]$ & $34(55.7)[61]^{*}$ & $93(72.1)[129]^{*}$ & $13(86.7)[15]$ & $42(71.2)[59]$ \\
\hline \multicolumn{5}{|l|}{ Comorbidities, $n(\%)[N]^{\dagger}$} \\
\hline Cardiovascular disease & $1(0.7)[146]^{*}$ & $12(4.4)[274]^{*}$ & $1(2.8)[36]$ & $8(5.0)[161]$ \\
\hline Malignancy & $9(6.2)[146]$ & $19(6.9)[274]$ & $4(11.1)[36]$ & $17(10.6)[161]$ \\
\hline Serious infection & $4(3.3)[121]$ & $7(3.1)[229]$ & $1(3.1)[32]$ & $7(5.1)[138]$ \\
\hline Diabetes & $5(3.4)[146]$ & $11(4.0)[274]$ & $3(8.3)[36]$ & $13(8.1)[161]$ \\
\hline mHAQ, mean (SD) score $[N]$ & $0.2(0.4)[144]$ & $0.2(0.4)[266]$ & $0.3(0.4)[36]$ & $0.3(0.3)[157]$ \\
\hline CDAI, mean (SD) score & $3.7(2.9)[146]$ & $3.5(3.0)[274]$ & $5.0(3.0)[36]$ & $4.4(2.9)[161]$ \\
\hline \multicolumn{5}{|l|}{ CDAI category, $n(\%)$} \\
\hline Remission & $68(46.6)$ & $147(53.6)$ & $11(30.6)$ & $59(36.6)$ \\
\hline LDA & $78(53.4)$ & $127(46.4)$ & $25(69.4)$ & $102(63.4)$ \\
\hline PGA, mean (SD) score & $7.7(7.9)$ & $7.0(9.1)$ & $10.5(10.4)$ & $8.9(8.8)$ \\
\hline Current prednisone use, $n(\%)$ & $15(10.3)$ & $29(10.6)$ & $9(25.0)^{*}$ & $16(9.9)^{*}$ \\
\hline \multicolumn{5}{|l|}{ No. prior bDMARDs, $n(\%)$} \\
\hline 0 & $146(100)$ & $274(100)$ & 0 & 0 \\
\hline 1 & 0 & 0 & $33(91.7)^{*}$ & $117(72.7)^{*}$ \\
\hline$>1$ & 0 & 0 & $3(8.3)^{*}$ & $44(27.3)^{*}$ \\
\hline
\end{tabular}

$a C C P$, anti-cyclic citrullinated peptide; $b D M A R D$, biologic disease-modifying antirheumatic drug; $C D A I$, Clinical Disease Activity Index; $E T N$, etanercept; $m H A Q$, modified Health Assessment Questionnaire; $P G A$, physician global assessment; $R A$, rheumatoid arthritis; $R F$, rheumatoid factor; $T N F i$, tumor necrosis factor inhibitor

$* p<0.05$ for ETN monotherapy versus other TNFi monotherapy

${ }^{\dagger}$ History of or current disease as assessed at index date, during the evaluation of index and baseline characteristics

Table 2 Time on therapy before achieving remission/LDA and before discontinuing csDMARD among bDMARD-naïve and bDMARD-experienced patients

\begin{tabular}{|c|c|c|c|c|}
\hline \multirow[t]{2}{*}{ Time, mean (SD), months } & \multicolumn{2}{|c|}{ bDMARD-naïve patients } & \multicolumn{2}{|c|}{ bDMARD-experienced patients } \\
\hline & $\operatorname{ETN}(n=146)$ & Other TNFi $(n=274)$ & $\operatorname{ETN}(n=36)$ & Other TNFi $(n=161)$ \\
\hline Time on TNFi therapy before achieving remission/LDA & $4.8(5.0)$ & $6.0(11.5)$ & $8.7(9.2)^{*}$ & $5.7(6.8)^{*}$ \\
\hline Time on csDMARD before achieving remission/LDA & $19.1(21.4)$ & $19.7(22.6)$ & $27.7(25.3)$ & $23.1(24.8)$ \\
\hline Time in remission/LDA before discontinuation of csDMARD & $19.0(25.5)$ & $15.9(23.1)$ & $10.6(13.3)$ & $18.4(26.6)$ \\
\hline Time on csDMARD before discontinuation of csDMARD & $36.3(32.7)$ & $38.6(32.7)$ & $41.8(31.9)$ & $39.1(32.3)$ \\
\hline $\begin{array}{l}\text { Time on combination therapy before discontinuation of csD- } \\
\text { MARD }\end{array}$ & $23.0(25.1)$ & $26.1(26.9)$ & $22.8(18.9)$ & $21.8(24.7)$ \\
\hline
\end{tabular}

DDMARD, biologic disease-modifying antirheumatic drug; $c S D M A R D$, conventional synthetic disease-modifying antirheumatic drug; ETN, etanercept; TNFi, tumor necrosis factor inhibitor

$* p<0.05$ for ETN monotherapy versus other TNFi monotherapy

bDMARD-naïve on other TNFis (46\%; risk difference was $11.9 \%$ [95\% CI 2.0\%, 21.9\%]; $p=0.02$ ). Among bDMARD-experienced patients, the proportion persistent on etanercept (50\%) at 6 months was numerically higher but not statistically significantly different from those persistent on other TNFis (43\%; risk difference was 6.5\% $[-11.5 \%, 24.6 \%] ; p=0.48)$. Similar results were seen in the 12-month cohort (Table 3), 
Table 3 Monotherapy persistence on index TNFi

\begin{tabular}{lllll}
\hline $\begin{array}{l}\text { Persistent on monotherapy after } \\
\text { discontinuing csDMARD, } n(\%)\end{array}$ & $\begin{array}{l}\text { ETN } \\
\text { monotherapy }\end{array}$ & $\begin{array}{l}\text { Other TNFi } \\
\text { monotherapy }\end{array}$ & Risk difference \% (95\% CI) & $p$ value \\
\hline $\begin{array}{l}\text { 6-month cohort } \\
\text { bDMARD-naïve }\end{array}$ & $84(58)$ & $125(46)$ & $11.9(2.0,21.9)$ & 0.02 \\
bDMARD-experienced & $18(50)$ & $70(43)$ & $6.5(-11.5,24.6)$ & 0.48 \\
All patients (stratified) & & & $10.8(2.1,19.6)$ & 0.02 \\
$\begin{array}{l}\text { 12-month cohort } \\
\text { bDMARD-naïve }\end{array}$ & $46(47)$ & $72(36)$ & $11.1(-0.8,23.0)$ & 0.07 \\
bDMARD-experienced & $9(41)$ & $30(28)$ & $12.6(-9.7,34.9)$ & 0.24 \\
All patients (stratified) & & & $11.4(0.9,21.9)$ & 0.03 \\
\hline
\end{tabular}

DDMARD, biologic disease-modifying antirheumatic drug; csDMARD, conventional synthetic diseasemodifying antirheumatic drug; ETN, etanercept; $O R$, odds ratio; $T N F i$, tumor necrosis factor inhibitor

${ }^{a}$ Mantel-Haenszel test of homogeneity reveals that the risk differences between the bDMARD-naïve and bDMARD-experienced patients were not significantly different $(p=0.61)$

${ }^{\mathrm{b}}$ Mantel-Haenszel test of homogeneity reveals that the risk differences between the bDMARD-naïve and bDMARD-experienced patients were not significantly different $(p=0.85)$
In the 6-month cohort, the risk differences in the stratumspecific estimates between etanercept and other TNFis were similar between bDMARD-naïve and bDMARD-experienced patients based on the Mantel-Haenszel test of homogeneity ( $p=0.61$; Table 3 ). The difference in persistence at the 6-month visit between etanercept and other TNFis across the bDMARD-naïve and bDMARD-experienced patients had a stratified Mantel-Haenszel common risk difference of $10.8 \%$ (95\% CI 2.1\%, 19.6\%; $p=0.02)$. Similar results were seen in the 12-month cohort (Table 3).

\section{Predictors of remaining on monotherapy}

According to multivariable models conducted separately for etanercept and other TNFi monotherapy, being in remission at the index date (i.e., before discontinuing the csDMARD) was the strongest predictor of maintaining monotherapy with etanercept or with other TNFis (data not shown). For patients in remission at the index date, persistence on monotherapy was nearly twice that of patients not in remission (i.e., those with LDA). Conversely, every 10-year increase in age, every 1-unit increase in CDAI score, and every 1-unit (on a scale of 1-100) increase in PGA score were associated with decreased likelihood of persistence on both etanercept monotherapy and other TNFi monotherapy. History of cardiovascular disease was associated with decreased likelihood of persistence on other TNFi monotherapy in the multivariate model. Results from the bivariate analysis were similar.

\section{Treatment patterns}

The most common change to RA therapy during the 6 months after index date was the reintroduction of a csDMARD, which was more common among patients on other
TNFi monotherapies (45\%) than on patients on etanercept monotherapy (35\%), regardless of prior bDMARD exposure (Table 4). Similar results were observed at 12 months following index date.

\section{Discussion}

In this study, we investigated the persistence of etanercept monotherapy and that of other TNFi monotherapy after achieving remission/LDA on combination therapy with a csDMARD (typically methotrexate). For the overall patient group, etanercept monotherapy was found to be associated with greater persistence at 6 and 12 months (56\% and 46\%, respectively) than observed for other TNFi monotherapy (45\% and $33 \%$, respectively), with an intergroup difference favoring etanercept of $11.2 \%$ at 6 months and $12.6 \%$ at 12 months.

It is well known in clinical practice and in clinical trials that patients who are bDMARD-naïve will have a greater response to TNFi therapy than those with prior exposure to bDMARD [24]; therefore, persistence stratified by prior bDMARD exposure is important. This study found greater persistence among bDMARD-naïve patients for both etanercept monotherapy and other TNFis monotherapy groups. In analyses stratified by prior bDMARD experience, the intergroup difference favoring etanercept remained similar: $10.8 \%$ at 6 months and $11.4 \%$ at 12 months.

The extent of persistence observed in this analysis was similar to that previously reported [25-27]. In bDMARDnaïve patients (the majority receiving concomitant treatment with a csDMARD) with a mix of inflammatory rheumatic diseases ( $50 \%$ with RA), 12-month persistence of $>50 \%$ was reported in an Australian real-world study 
Table 4 Post-index treatment patterns

\begin{tabular}{llllll}
\hline & \multicolumn{2}{l}{ bDMARD-naïve } & & \multicolumn{2}{l}{ bDMARD-experienced } \\
\cline { 2 - 3 } Treatment pattern, $n(\%)$ & $\begin{array}{l}\text { ETN } \\
\text { monotherapy }\end{array}$ & $\begin{array}{l}\text { Other TNFi } \\
\text { monotherapy }\end{array}$ & & $\begin{array}{l}\text { ETN } \\
\text { monotherapy }\end{array}$ & $\begin{array}{l}\text { Other TNFi } \\
\text { monotherapy }\end{array}$ \\
\hline 6-month cohort, $N$ & 146 & 274 & 36 & 161 \\
Discontinued index bDMARD & $1(1)$ & $2(1)$ & & $1(3)$ & 0 \\
Switched to bDMARD & $6(4)$ & $8(3)$ & & $2(6)$ & $8(5)$ \\
Switched to csDMARD & $2(1)$ & $5(2)$ & & 0 & $2(1)$ \\
Added csDMARD & $50(34)$ & $119(43)$ & & $14(39)$ & $77(48)$ \\
Stopped all RA therapy & $3(2)$ & $15(5)$ & & $1(3)$ & $4(2)$ \\
12-month cohort, $N$ & 98 & 201 & & 22 & 106 \\
Discontinued index bDMARD & 0 & 0 & & $1(5)$ & $1(1)$ \\
Switched to bDMARD & $5(5)$ & $8(4)$ & & 0 & $6(6)$ \\
Switched to csDMARD & $3(3)$ & $4(2)$ & & 0 & $1(1)$ \\
Added csDMARD & $44(45)$ & $102(51)$ & & $12(55)$ & $62(58)$ \\
Stopped all RA therapy & 0 & $15(7)$ & 0 & $6(6)$ \\
\hline
\end{tabular}

DDMARD, biologic disease-modifying antirheumatic drug; $c s D M A R D$, conventional synthetic diseasemodifying antirheumatic drug; ETN, etanercept; $R A$, rheumatoid arthritis; $T N F i$, tumor necrosis factor inhibitor
[27]. In bDMARD-experienced patients with RA, persistence rates of approximately $40 \%$ have been reported [25, 26].

Using multivariate analysis, we found that remission was the major predictor of longer persistence; patients who achieved remission on combination therapy versus those who achieved LDA were almost twice as likely to have persistence on monotherapy. Others have reported a similar association between remission and persistency [28, 29]. Increasing age, higher CDAI scores, and higher PGA scores were associated with a reduced likelihood of persistence. Of these, only lower PGA scores were associated with an increased likelihood of persistent remission in other studies [28].

The differences between etanercept and other TNFi monotherapy in ongoing treatment persistence are of interest. Concerns have been raised over the therapeutic implications of the development of neutralizing antidrug antibodies to bDMARDs [15, 16], which may be the underlying rationale for recommending continuation with methotrexate monotherapy once good disease control has been achieved on combination therapy. The development of neutralizing antidrug antibodies to TNFis other than etanercept have been reported $[15,16,30-34]$, and may be one factor contributing to the different persistence rates detected in our study. Similarly, the higher discontinuation rates reported for other TNFis than for etanercept in long-term registry studies $[35,36]$ is consistent with our findings. Furthermore, we found that patients on etanercept monotherapy were less likely than those on other TNFi monotherapy to have a csDMARD added to treatment over 6 or 12 months to maintain disease control.

Overall, the findings from this study may help inform future guidelines on how best to manage patients who respond well to combination therapy [6]. Currently, the ACR and EULAR guidelines are not specific about whether continuation on a single agent after achievement of LDA or remission is considered appropriate [5, 6]. APLAR and the latest French guidelines recommend tapering or discontinuing the targeted therapy rather than the csDMARD $[7,37]$. However, randomized clinical trials show that the withdrawal of etanercept in patients who had achieved disease control with combination therapy was associated with a worsening of disease control [38, 39].

\section{Strengths and limitations}

As with any study using registry data, our study has strengths and limitations. One strength of the study is the use of realworld data from one of the largest RA registries in the world, which has been accumulating data from nearly every US state, including rural, urban, academic, and private practices. Another strength of the Corrona registry is the systematic collection of disease activity measures. The registry has a range of internal validity and reliability checks to ensure the accuracy and completeness of the measures of disease activity and disease severity, treatment, adverse event, and quality-of-life data entered at each visit [19].

In common with all observational studies, a limitation of this analysis is that patients were not randomly assigned to treatments; therefore, there is a risk of selection bias and confounding. Notably, the etanercept group was slightly younger, less likely to have had cardiovascular disease, and had less exposure to prior bDMARDs. We thus stratified for bDMARD exposure. Among the bDMARD-experienced group, etanercept patients were more likely to be current users of prednisone than other TNFi patients. This 
imbalance in prednisone use based on a small sample of 36 bDMARD-experienced etanercept patients is in contrast to the several-fold larger sample of bDMARD- naïve patients where prednisone use was similar for etanercept $(n=146)$ and other TNFi $(n=274)$ patients $(10.3 \%$ versus $10.6 \%$; $p>0.999)$. We note that we did not adjust explicitly for the number of prior bDMARDs received; however, the results reported are meant to describe the differences between the two groups, including the differences in the baseline factors that may determine treatment decisions and may influence persistency with monotherapy.

The generalizability of results is also a potential area for concern. However, previous analysis of the Corrona database has demonstrated that the demographics and comorbidity profiles of patients included in the database were similar to patients with RA not included in the database [40].

Finally, in our analysis, we did not account for the degree of disease activity before the initiation of combination therapy csDMARD plus TNFi therapy, a factor which may prove to be a predictor of successful transition to TNFi monotherapy. However, there was no difference between treatment groups in disease activity at the time of discontinuing the csDMARD therapy in patients with remission/LDA.

\section{Conclusions}

This study provides real-world evidence that a subset of patients who achieved remission or LDA when treated with a combination of csDMARD and TNFi were able to successfully transition to TNFi monotherapy (etanercept or other TNFi). Persistence with TNFi monotherapy was twice as likely in patients who achieved remission versus those with LDA. In this real-world setting, etanercept monotherapy was associated with greater persistence than was observed for other TNFi monotherapy, and a lower likelihood of requiring reintroduction of a csDMARD.

Acknowledgements Dikran Toroser (Amgen Inc.), Lee Hohaia and Rick Davis (ICON plc, funded by Amgen Inc.) provided medical writing support.

Author contributions Study design and interpretation: DAP, HJL, TL, EK, SR, WH, and NAA. Statistical analysis: HJL, SR, and WH. Interpretation: EK, GK and SS. Critical revision of the manuscript: all authors. Final approval of the version to be published: all authors. Agree to be held accountable for all aspects of the work in ensuring that questions related to the accuracy or integrity of any part of the work are appropriately investigated and resolved: all authors.

Funding This study was sponsored by Corrona, LLC, and the analysis was funded by Amgen Inc. Access to study data was limited to Corrona, and Corrona statisticians completed all of the analysis; all authors contributed to the interpretation of the results. Corrona has been supported through contracted subscriptions in the last two years by AbbVie, Amgen, Boehringer Ingelheim, Bristol-Myers Squibb, Celgene, Eli Lilly and Company, Genentech, Gilead, Janssen, Merck, Novartis, Ortho Dermatologics, Pfizer Inc, Regeneron, and Sun.

\section{Compliance with ethical standards}

Conflict of interest Dimitrios A. Pappas is an employee of Corrona, LLC; has been a consultant/received honoraria for Novartis, Genentech/Roche, Sanofi/Regeneron, and AbbVie; has equity interest in Corrona, LLC; and is on the board of directors for Corrona Research Foundation. Heather Litman is an employee and shareholder at Corrona, LLC; Tamara Lesperance is a contractor for and has received salary support from Amgen Inc.; Greg Kricorian is an employee and shareholder of Amgen Inc.; Elaine Karis is an employee and shareholder of Amgen Inc.; Sabrina Rebello is an employee of Corrona, LLC. Winnie Hua is an employee of Corrona, LLC. Neil A. Accortt is an employee and shareholder of Amgen Inc. Scott Stryker is an employee and shareholder of Amgen Inc.

Ethics approval All participating investigators obtained full institutional review board (IRB) approval for human subject research. Sponsor approval and continuing review were obtained through a central IRB (New England Independent Review Board, NEIRB No. 120160610; approved annually on July 28, 2016; July 27, 2017; August 7, 2018; and July 30, 2019). For academic investigative sites without a waiver to use the central IRB, full board approval was obtained from the respective governing IRBs; documentation of approval was submitted to the Sponsor before initiating any study procedures.

Informed consent All registry participants provided written informed consent before participating.

Data sharing The Corrona dataset is based on a large US multicenter study adhering to a number of institutional review boards, with complex logistics. Patients did not provide consent to raw data sharing during the data collection for this purpose, and the Corrona data sharing policies do not permit raw data sharing for this purpose. An aggregated limited dataset from the current analyses is available to qualified investigators with an approved protocol. Data requests may be sent to Corrona, represented by Dr. Jeffrey D. Greenberg, MD, MPH, New York University School of Medicine, New York, NY, e-mail jgreenberg@ corrona.org.

Open Access This article is licensed under a Creative Commons Attribution 4.0 International License, which permits use, sharing, adaptation, distribution and reproduction in any medium or format, as long as you give appropriate credit to the original author(s) and the source, provide a link to the Creative Commons licence, and indicate if changes were made. The images or other third party material in this article are included in the article's Creative Commons licence, unless indicated otherwise in a credit line to the material. If material is not included in the article's Creative Commons licence and your intended use is not permitted by statutory regulation or exceeds the permitted use, you will need to obtain permission directly from the copyright holder. To view a copy of this licence, visit http://creativecommons.org/licenses/by/4.0/.

\section{References}

1. Aletaha D, Smolen JS (2018) Diagnosis and management of rheumatoid arthritis: a review. JAMA 320(13):1360-1372. https://doi. org/10.1001/jama.2018.13103 
2. Smolen JS, Aletaha D, Barton A, Burmester GR, Emery P, Firestein GS, Kavanaugh A, McInnes IB, Solomon DH, Strand V, Yamamoto K (2018) Rheumatoid arthritis. Nat Rev Dis Primers 4:18001. https://doi.org/10.1038/nrdp.2018.1

3. Myasoedova E, Crowson CS, Kremers HM, Therneau TM, Gabriel SE (2010) Is the incidence of rheumatoid arthritis rising?: Results from Olmsted County, Minnesota, 1955-2007. Arthritis Rheum 62(6):1576-1582. https://doi.org/10.1002/art.27425

4. Rudan I, Sidhu S, Papana A, Meng SJ, Xin-Wei Y, Wang W, Campbell-Page RM, Demaio AR, Nair H, Sridhar D, Theodoratou E, Dowman B, Adeloye D, Majeed A, Car J, Campbell H, Wang W, Chan KY, Global Health Epidemiology Reference Group (2015) Prevalence of rheumatoid arthritis in low- and middleincome countries: a systematic review and analysis. J Glob Health 5(1):010409. https://doi.org/10.7189/jogh.05.010409

5. Smolen JS, Landewe R, Bijlsma J, Burmester G, Chatzidionysiou K, Dougados M, Nam J, Ramiro S, Voshaar M, van Vollenhoven $\mathrm{R}$, Aletaha D, Aringer M, Boers M, Buckley CD, Buttgereit F, Bykerk V, Cardiel M, Combe B, Cutolo M, van Eijk-Hustings Y, Emery P, Finckh A, Gabay C, Gomez-Reino J, Gossec L, Gottenberg JE, Hazes JMW, Huizinga T, Jani M, Karateev D, Kouloumas M, Kvien T, Li Z, Mariette X, McInnes I, Mysler E, Nash P, Pavelka K, Poor G, Richez C, van Riel P, Rubbert-Roth A, Saag K, da Silva J, Stamm T, Takeuchi T, Westhovens R, de Wit M, van der Heijde D (2017) Eular recommendations for the management of rheumatoid arthritis with synthetic and biological disease-modifying antirheumatic drugs: 2016 update. Ann Rheum Dis 76(6):960-977. https://doi.org/10.1136/annrheumdis-2016210715

6. Singh JA, Saag KG, Bridges SL Jr, Akl EA, Bannuru RR, Sullivan MC, Vaysbrot E, McNaughton C, Osani M, Shmerling RH, Curtis JR, Furst DE, Parks D, Kavanaugh A, O’Dell J, King C, Leong A, Matteson EL, Schousboe JT, Drevlow B, Ginsberg S, Grober J, St Clair EW, Tindall E, Miller AS, McAlindon T (2016) 2015 American College of Rheumatology guideline for the treatment of rheumatoid arthritis. Arthritis Rheumatol 68(1):1-26. https:// doi.org/10.1002/art.39480

7. Lau CS, Chia F, Dans L, Harrison A, Hsieh TY, Jain R, Jung SM, Kishimoto M, Kumar A, Leong KP, Li Z, Lichauco JJ, Louthrenoo W, Luo SF, Mu R, Nash P, Ng CT, Suryana B, Wijaya LK, Yeap SS (2019) 2018 update of the APLAR recommendations for treatment of rheumatoid arthritis. Int J Rheum Dis 22(3):357-375. https://doi.org/10.1111/1756-185X.13513

8. Grijalva CG, Chung CP, Arbogast PG, Stein CM, Mitchel EF, Jr., Griffin MR (2007) Assessment of adherence to and persistence on disease-modifying antirheumatic drugs (DMARDs) in patients with rheumatoid arthritis. Med Care 45 (10 Suppl 2):S66-76. https://doi.org/10.1097/MLR.0b013e318041384c

9. Salliot C, van der Heijde D (2009) Long-term safety of methotrexate monotherapy in patients with rheumatoid arthritis: a systematic literature research. Ann Rheum Dis 68(7):1100-1104. https ://doi.org/10.1136/ard.2008.093690

10. Costello R, David T, Jani M (2019) Impact of adverse events associated with medications in the treatment and prevention of rheumatoid arthritis. Clin Ther 41(7):1376-1396. https://doi. org/10.1016/j.clinthera.2019.04.030

11. Choy E, Aletaha D, Behrens F, Finckh A, Gomez-Reino J, Gottenberg JE, Schuch F, Rubbert-Roth A (2017) Monotherapy with biologic disease-modifying anti-rheumatic drugs in rheumatoid arthritis. Rheumatol (Oxf) 56(5):689-697. https://doi. org/10.1093/rheumatology/kew271

12. Aaltonen KJ, Turunen JH, Sokka T, Puolakka K, Valleala H (2016) A survey on the medication adherence to methotrexate among rheumatoid arthritis patients treated with self-administered biologic drugs. Clin Exp Rheumatol 34(4):694-697
13. Moreland LW, Schiff MH, Baumgartner SW, Tindall EA, Fleischmann RM, Bulpitt KJ, Weaver AL, Keystone EC, Furst DE, Mease PJ, Ruderman EM, Horwitz DA, Arkfeld DG, Garrison L, Burge DJ, Blosch CM, Lange ML, McDonnell ND, Weinblatt ME (1999) Etanercept therapy in rheumatoid arthritis. A randomized, controlled trial. Ann Intern Med 130(6):478-486. https ://doi.org/10.7326/0003-4819-130-6-199903160-00004

14. Dinarello CA (2005) Differences between anti-tumor necrosis factor-alpha monoclonal antibodies and soluble TNF receptors in host defense impairment. J Rheumatol Suppl 74:40-47

15. Bartelds GM, Krieckaert CL, Nurmohamed MT, van Schouwenburg PA, Lems WF, Twisk JW, Dijkmans BA, Aarden L, Wolbink GJ (2011) Development of antidrug antibodies against adalimumab and association with disease activity and treatment failure during long-term follow-up. JAMA 305(14):1460-1468. https://doi.org/10.1001/jama.2011.406

16. Krieckaert CL, Jamnitski A, Nurmohamed MT, Kostense PJ, Boers M, Wolbink G (2012) Comparison of long-term clinical outcome with etanercept treatment and adalimumab treatment of rheumatoid arthritis with respect to immunogenicity. Arthritis Rheum 64(12):3850-3855. https://doi.org/10.1002/art.34680

17. Enbrel (2018) Etanercept. Immunex Corporation, Thousand Oaks

18. Inui K, Koike $\mathrm{T}$ (2016) Combination therapy with biologic agents in rheumatic diseases: current and future prospects. Ther $\mathrm{Adv}$ Musculoskelet Dis 8(5):192-202. https://doi.org/10.1177/17597 20X16665330

19. Kremer JM (2016) The Corrona US Registry of rheumatic and autoimmune diseases. Clin Exp Rheumatol 34(5 Suppl 101):S96-S99

20. Aletaha D, Smolen J (2005) The simplified disease activity index (SDAI) and the clinical disease activity index (CDAI): a review of their usefulness and validity in rheumatoid arthritis. Clin Exp Rheumatol 23(5 Suppl 39):S100-108

21. Luttropp K, Dozier M, Justo N, Cornillie F, Kachroo S, Govoni M, Salomonsson S, Black CM, Khalifa A (2019) Real-world treatment persistence of golimumab in the management of immunemediated rheumatic diseases in Europe: a systematic literature review. BMJ Open 9(5):e027456. https://doi.org/10.1136/bmjop en-2018-027456

22. Svedbom A, Dalen J, Black CM, Kachroo S (2017) Persistence and costs with subcutaneous TNF-alpha inhibitors in immunemediated rheumatic disease stratified by treatment line. Patient Prefer Adherence 11:95-106. https://doi.org/10.2147/PPA.S1198 08

23. Mease PJ, Karki C, Liu M, Li Y, Gershenson B, Feng H, Hur P, Greenberg JD (2019) Discontinuation and switching patterns of tumour necrosis factor inhibitors (TNFis) in TNFi-naive and TNFi-experienced patients with psoriatic arthritis: an observational study from the US-based Corrona registry. RMD Open 5(1):e000880. https://doi.org/10.1136/rmdopen-2018-000880

24. Mori S, Yoshitama T, Ueki Y (2018) Tofacitinib therapy for rheumatoid arthritis: a direct comparison study between biologic-naive and experienced patients. Intern Med 57(5):663-670. https://doi. org/10.2169/internalmedicine.9341-17

25. Chastek B, Chen CI, Proudfoot C, Shinde S, Kuznik A, Wei W (2017) Treatment persistence and healthcare costs among patients with rheumatoid arthritis changing biologics in the USA. Adv Ther 34(11):2422-2435. https://doi.org/10.1007/s1232 5-017-0617-5

26. Wei W, Knapp K, Wang L, Chen CI, Craig GL, Ferguson K, Schwartzman S (2017) Treatment persistence and clinical outcomes of tumor necrosis factor inhibitor cycling or switching to a new mechanism of action therapy: real-world observational study of rheumatoid arthritis patients in the United States with prior tumor necrosis factor inhibitor therapy. Adv Ther 34(8):19361952. https://doi.org/10.1007/s12325-017-0578-8 
27. Tymms K, Littlejohn G, Griffiths H, de Jager J, Bird P, Joshua F, Nash P, Handel M, McManus H, Butcher BE, Youssef P (2018) Treatment patterns among patients with rheumatic disease (rheumatoid arthritis (RA), ankylosing spondylitis (AS), psoriatic arthritis (PSA) and undifferentiated arthritis (UNA) treated with subcutaneous TNF inhibitors. Clin Rheumatol 37(6):1617-1623. https://doi.org/10.1007/s10067-018-4105-3

28. Yu C, Jin S, Wang Y, Jiang N, Wu C, Wang Q, Tian X, Li M, Zeng $X$ (2019) Remission rate and predictors of remission in patients with rheumatoid arthritis under treat-to-target strategy in realworld studies: a systematic review and meta-analysis. Clin Rheumatol 38(3):727-738. https://doi.org/10.1007/s10067-018-4340-7

29. Keystone EC, Pope JE, Thorne JC, Poulin-Costello M, PhanChronis K, Vieira A, Haraoui B, Investigators C (2016) Twoyear radiographic and clinical outcomes from the Canadian Methotrexate and Etanercept Outcome study in patients with rheumatoid arthritis. Rheumatol (Oxf) 55(2):327-334. https:// doi.org/10.1093/rheumatology/kev338

30. Dore RK, Mathews S, Schechtman J, Surbeck W, Mandel D, Patel A, Zhou L, Peloso P (2007) The immunogenicity, safety, and efficacy of etanercept liquid administered once weekly in patients with rheumatoid arthritis. Clin Exp Rheumatol 25(1):40-46

31. Weinblatt ME, Schiff MH, Ruderman EM, Bingham CO 3rd, Li J, Louie J, Furst DE (2008) Efficacy and safety of etanercept 50 mg twice a week in patients with rheumatoid arthritis who had a suboptimal response to etanercept $50 \mathrm{mg}$ once a week: Results of a multicenter, randomized, double-blind, active drug-controlled study. Arthritis Rheum 58(7):1921-1930. https://doi.org/10.1002/ art. 23493

32. Jamnitski A, Krieckaert CL, Nurmohamed MT, Hart MH, Dijkmans BA, Aarden L, Voskuyl AE, Wolbink GJ (2012) Patients non-responding to etanercept obtain lower etanercept concentrations compared with responding patients. Ann Rheum Dis 71(1):88-91. https://doi.org/10.1136/annrheumdis-2011-200184

33. Moots RJ, Xavier RM, Mok CC, Rahman MU, Tsai WC, Al-Maini MH, Pavelka K, Mahgoub E, Kotak S, Korth-Bradley J, Pedersen R, Mele L, Shen Q, Vlahos B (2017) The impact of anti-drug antibodies on drug concentrations and clinical outcomes in rheumatoid arthritis patients treated with adalimumab, etanercept, or infliximab: results from a multinational, real-world clinical practice, non-interventional study. PLoS One 12(4):e0175207. https ://doi.org/10.1371/journal.pone.0175207

34. Maid PJ, Xavier R, Real RM, Pedersen R, Shen Q, Marshall L, Solano G, Borlenghi CE, Hidalgo RP (2018) Incidence of antidrug antibodies in rheumatoid arthritis patients from Argentina treated with adalimumab, etanercept, or infliximab in a real-world setting. J Clin Rheumatol 24(4):177-182. https://doi.org/10.1097/ RHU.0000000000000612
35. Neovius M, Arkema EV, Olsson H, Eriksson JK, Kristensen LE, Simard JF, Askling J, The ARTIS Study Group (2015) Drug survival on TNF inhibitors in patients with rheumatoid arthritis comparison of adalimumab, etanercept and infliximab. Ann Rheum Dis 74(2):354-360. https://doi.org/10.1136/annrheumdis-2013204128

36. Hetland ML, Christensen IJ, Tarp U, Dreyer L, Hansen A, Hansen IT, Kollerup G, Linde L, Lindegaard HM, Poulsen UE, Schlemmer A, Jensen DV, Jensen S, Hostenkamp G, Ostergaard M, All Departments of Rheumatology in Denmark (2010) Direct comparison of treatment responses, remission rates, and drug adherence in patients with rheumatoid arthritis treated with adalimumab, etanercept, or infliximab: Results from eight years of surveillance of clinical practice in the nationwide danish danbio registry. Arthritis Rheum 62(1):22-32. https://doi.org/10.1002/art.27227

37. Daien C, Hua C, Gaujoux-Viala C, Cantagrel A, Dubremetz M, Dougados M, Fautrel B, Mariette X, Nayral N, Richez C, Saraux A, Thibaud G, Wendling D, Gossec L, Combe B (2019) Update of French Society for Rheumatology recommendations for managing rheumatoid arthritis. Joint Bone Spine 86(2):135-150. https://doi. org/10.1016/j.jbspin.2018.10.002

38. Smolen JS, Nash P, Durez P, Hall S, Ilivanova E, Irazoque-Palazuelos F, Miranda P, Park MC, Pavelka K, Pedersen R, Szumski A, Hammond C, Koenig AS, Vlahos B (2013) Maintenance, reduction, or withdrawal of etanercept after treatment with etanercept and methotrexate in patients with moderate rheumatoid arthritis (preserve): a randomised controlled trial. Lancet 381(9870):918929. https://doi.org/10.1016/S0140-6736(12)61811-X

39. van Vollenhoven RF, Ostergaard M, Leirisalo-Repo M, Uhlig T, Jansson M, Larsson E, Brock F, Franck-Larsson K (2016) Full dose, reduced dose or discontinuation of etanercept in rheumatoid arthritis. Ann Rheum Dis 75(1):52-58. https://doi.org/10.1136/ annrheumdis-2014-205726

40. Curtis JR, Chen L, Bharat A, Delzell E, Greenberg JD, Harrold L, Kremer J, Setoguchi S, Solomon DH, Xie F, Yun H (2014) Linkage of a de-identified United States rheumatoid arthritis registry with administrative data to facilitate comparative effectiveness research. Arthritis Care Res (Hoboken) 66(12):1790-1798. https ://doi.org/10.1002/acr.22377

Publisher's Note Springer Nature remains neutral with regard to jurisdictional claims in published maps and institutional affiliations. 